\title{
Anemia Blunts the Thermogenic Response to Environmental Cold Stress in Newborn Piglets
}

\author{
STEVEN R. MAYFIELD, ${ }^{1}$ PHILIP W. SHAUL, ${ }^{1}$ WILLIAM OH, AND BARBARA S. STONESTREET \\ Brown University Program in Medicine, Department of Pediatrics, Women and Infants Hospital of Rhode Island, \\ Providence, Rhode Island 02908
}

\begin{abstract}
We tested the hypothesis that isovolemic anemia blunts the thermogenic response to environmental cold stress in 3 to 4-day-old newborn piglets. Eight animals were studied in both thermoneutral $\left(31.6-32.8^{\circ} \mathrm{C}\right)$ and cold (19.6-20.2 $\mathrm{C}$ ) environments, before and after an isovolemic, partial volume exchange transfusion which reduced the hematocrit from 26 to $15 \%$. In the nonanemic phase of study, deep rectal temperatures declined but had plateaued by 30 minutes after onset of cold stress and remained within normal limits for newborn piglets. In the anemic phase of study, deep rectal temperature declined continuously throughout cold stress with true body core hypothermia $\left(<38^{\circ} \mathrm{C}\right)$ observed at all measurement points beyond $15 \mathrm{~min}$ of cold stress. Baseline oxygen consumption did not differ between the two study phases $(17.6 \pm 1.8$ versus $16.7 \pm 2.1 \mathrm{ml} / \mathrm{kg}^{-1} / \mathrm{min}^{-1}$, mean $\pm \mathrm{SEM}$ ). However, during environmental cold stress, oxygen consumption increased by $64 \%$ over baseline in the nonanemic phase of study $(p<0.05)$ whereas $21 \%$ increase over baseline was observed in the anemic phase ( $p$ NS). We conclude that isovolemic anemia limited oxygen consumption and heat production during environmental cold stress, resulting in body core hypothermia. (Pediatr Res 21: 482-486, 1987
\end{abstract}

\section{Abbreviations}

$\dot{\mathrm{VO}}_{2}$, oxygen consumption

$\mathrm{CaO}_{2}$, arterial oxygen content

$\mathrm{CrO}_{2}$, mixed venous oxygen content

$T_{0}$, baseline deep rectal temperature

$T_{x}$, cold stress deep rectal temperature

HCT, hematocrit

The homeothermic response of newborn animals and humans to environmental cold stress includes increased oxygen consumption with concomitant heat production (1-3). Thus, successful thermogenesis constitutes a state of increased oxygen demand and, without a proportionate increase in oxygen availability, will decrease the oxygen availability-to-demand ratio (4). In this situation, a reduction in oxygen availability may prevent a successful thermogenic response to environmental cold stress, resulting in body core hypothermia. Anemia or hypoxemia reduces oxygen-carrying capacity and may result in such a limitation of oxygen consumption and heat production. Isovolemic anemia, where hemoglobin levels have been reduced to less than

Received May 1, 1986; accepted December 15, 1986.

Reprint address Barbara S. Stonestreet, M.D., Women and Infants Hospital of Rhode Island, Department of Pediatrics, 50 Maude Street, Providence, RI 02908.

Supported in part by Training in Perinatal Biology Grant 1 T32HDO7232-03, National Institutes of Child Health and Human Development, Bethesda, MD.

${ }^{1}$ Present address Department of Pediatrics, University of Texas Health Science Center, 5323 Harry Hines Boulevard, Dallas, TX 75235.
$5 \mathrm{~g} / \mathrm{dl}$, has been shown to decrease basal oxygen consumption in newborn lambs (5). Similar decreases in oxygen consumption have been demonstrated in adult dogs when the hematocrit was less than $10 \%(6-8)$. Scopes and Ahmed (9), in a study of infants with hypoxemia, observed a blunting of the thermogenic response to cold stress when the $\mathrm{pO}_{2}$ was less than $50 \mathrm{~mm} \mathrm{Hg}$ and complete ablation when the $\mathrm{pO}_{2}$ was less than $30 \mathrm{~mm} \mathrm{Hg}$. All of these studies depict severe reductions in oxygen availability. The effect of isovolemic anemia, of a magnitude which does not alter basal oxygen consumption, on the thermogenic response to environmental cold stress has not been tested. Therefore, the purpose of this study was to test the hypothesis that anemia blunts the thermogenic response to environmental cold stress, resulting in body core hypothermia.

\section{MATERIALS AND METHODS}

Eight, 2- to 3-day-old, farm-bred piglets were obtained from a local breeder who provided accurate time of farrowing. The weight of the piglets was $1.29 \pm 0.2 \mathrm{~kg}$ (mean $\pm \mathrm{SD}$ ).

Surgical procedure. Twenty-four h before study, each animal underwent surgery using $70 \%$ nitrous oxide- $30 \%$ oxygen inhalation anesthesia and $1 \%$ xylocaine local anesthesia. Polyvinyl catheters were placed in the upper abdominal aorta via one femoral artery, the lower abdominal aorta via the opposite femoral artery, the right atrium via the femoral vein, and the left ventricle via the left carotid artery. Previous work has shown that use of the carotid artery for catheterization of the left ventricle does not alter brain blood flow (10). An 8 French gastroesophageal feeding catheter was placed and secured, and a vinyl-covered, flexible, electronic thermistor probe inserted into the rectum to a depth of $7 \mathrm{~cm}$. Postoperatively, $5 \%$ dextrose 10 $\mathrm{ml} / \mathrm{kg}$ and Ampicillin $100 \mathrm{mg} / \mathrm{kg}$ were given intravenously and each vascular catheter was filled with a solution containing heparin $100 \mathrm{U} / \mathrm{ml}$. Placement of catheters was verified at autopsy.

Animal preparation. Immediately following surgery, each animal was placed in plexiglass test chamber with wall 3-mm thick. The floor was covered with a gauze mattress. The dimensions of the chambers were $10 \mathrm{~cm}$ wide $\times 22.5 \mathrm{~cm}$ long $\times 30 \mathrm{~cm}$ high. This space allowed the animal adequate room to lie prone, stand, or stretch without touching the walls of the chamber. An electronic air temperature probe was placed at the rear of the chamber, near the top where it was not touching either the animal or the walls of the chamber. Catheters and probe wires were directed through a central porthole in the top of the chamber. Air was entrained through open seams and portholes in the chamber by means of a vacuum pump. (Thomas Ind., Sheboygan, WI) connected by Tygon tubing to a porthole in the front wall. Air flow was regulated with a flowmeter (Labcrest Century 100 , Warminster, PA) which had been calibrated against a watersealed spirometer over a range of $1-24 \mathrm{liter} / \mathrm{min}$. Air flow was maintained at 7 liter/min to avoid the accumulation of expired 
gases within the chamber. The test chamber was placed inside an incubator (Air Shields Model C-35, Hatboro, PA) and the air temperature maintained at 30 to $33^{\circ} \mathrm{C}$. This range of air temperatures allowed the piglets to maintain deep rectal temperatures between 38.5 and $39.5^{\circ} \mathrm{C}$, the normal core temperature of the newborn piglet $(1,11,12)$. The incubator was covered with dark sheets to minimize external stimuli and prevent agitation of the animal. The study apparatus provided a thermoneutral, quiet environment while allowing for nondisruptive surveillance and feeding.

Animals were fed with $5 \%$ dextrose $30 \mathrm{ml} / \mathrm{kg}$ via the gastroesophageal catheter every 4 to $6 \mathrm{~h}$ with the last feeding given 3 to $4 \mathrm{~h}$ before the onset of study so as to avoid the effect of dietinduced thermogenesis on the study observations.

Experimental protocol. Each animal was studied during two consecutive phases; a nonanemic phase and an anemic phase. Two series of determinations were made in each phase of study; each series included measurements of deep rectal and environmental temperatures, cardiac output, arterial and mixed-venous oxygen contents, arterial blood gases (corrected for body temperature), and hematocrit. Arterial oxygen content was sampled from the catheter in the upper abdominal aorta (13). Mixed venous oxygen content was sampled from the right atrial catheter $(14,15)$. Additional deep rectal and environmental temperatures as well as mean arterial blood pressure and heart rate were measured every 15 min during both phases of study. In the first phase of study (nonanemic), baseline measurements were made while in a thermoneutral environment. The environmental temperature was then lowered to 18 to $22^{\circ} \mathrm{C}$ over $20-30 \mathrm{~min}$. This range of cold air temperatures was expected to elicit a $100 \%$ increase in oxygen consumption in piglets 3 to 4 days old (1). Repeat measurements as described were made 30 min after reaching the nadir of the air temperature $(60 \mathrm{~min}$ after onset of cold stress). The environmental temperature was then returned to baseline levels and the animals recovered for $1 \mathrm{~h}$. At that point, an isovolemic, partial volume exchange transfusion was performed with the goal of reducing the hematocrit to approximately $15 \%$. The amount of blood exchanged for plasma was calculated for each piglet using the equation:

$$
\text { Volume exchange }=\frac{(95 \mathrm{ml} / \mathrm{kg})(\Delta \mathrm{HCT})}{\text { Preexchange HCT }}
$$

Care was taken during each exchange transfusion to infuse and withdraw blood at equivalent rates (approximately $2 \mathrm{ml} / \mathrm{min}$ ) to avoid transient hypo/hypervolemia. Heart rate, mean arterial blood pressure, and deep rectal temperature were monitored continuously and remained stable throughout each procedure. Following each exchange transfusion, a 2-h time period elapsed before entry into the second phase of study. In this second phase, (anemic), experimental measurements and manipulations were identical to the first phase and included measurements in a baseline, thermoneutral environment, and after $30 \mathrm{~min}$ at the nadir of the air temperature; i.e. after $60 \mathrm{~min}$ of environmental cold stress. The total elapsed time for each study was $5 \mathrm{~h}$. All blood withdrawn for sampling $(5 \mathrm{ml}$ per measurement point) was replaced with donor piglet blood having a similar hematocrit. The donor piglets were 2 to 4 days old, the same age as the study piglets. Previous work has shown that no significant changes occur in the P50 of piglet blood obtained between 2 and 4 days of age (16). At the end of each study, the animal was killed by intravenous injection of sodium thiamylal.

In order to determine the effect of the exchange transfusion alone on the responses to environmental cold stress, three piglets ( 3 days old, weight $1.23 \pm 0.10 \mathrm{~kg}$ ) completed the experimental protocol before and after a sham exchange transfusion during which the hematocrit remained unchanged (26.2 versus $27.3 \%$, $p$ NS). The sham exchange transfusion consisted of removal of whole blood and infusion of whole blood having the same hematocrit, following the previously outlined procedure. No differences were observed between the phases in either baseline or the cold stress measurements (data not shown). We concluded that the exchange transfusion, per se, did not affect the experimental observations in the second phase of the study.

Methodology. Cardiac output was measured with radiolabeled microspheres using established techniques $(17,18)$. Oxygen contents were measured in duplicate on a $\mathrm{Lex}-\mathrm{O}_{2}$-Con instrument (Lexington Instruments, Waltham, MA). Blood pressure and heartrate were measured using a pressure transducer (HewlettPackard, model $1280 \mathrm{C}$, Lexington, MA) from a catheter placed in the lower abdominal aorta. Measurements so obtained were recorded on a polygraph (Hewlett-Packard, 7754 series). Deep rectal temperature was measured with an electronic, thermistor probe (Yellow Springs Instruments, model 402, Yellow Springs, $\mathrm{OH})$. Environmental temperature was measured with an electronic, air temperature probe (YSI model 408). Both probes were connected to a six-channel, electronic telethermometer (YSI 46TUC). Each probe had been tested against a certified mercury thermometer (National Bureau of Standards) in a water bath. Linear regression equations were individually derived for both probes to predict true temperature for the range tested $\left(30-40^{\circ}\right.$ $\mathrm{C}$ for the rectal probe and $10-40^{\circ} \mathrm{C}$ for the air probe).

Data analysis. $\mathrm{VO}_{2}$ and oxygen extraction were calculated from measured values using the following equations:

$$
\begin{aligned}
& \dot{\mathrm{VO}_{2}}(\mathrm{ml} / \mathrm{min})=\text { cardiac output } \cdot\left(\mathrm{CaO}_{2}-\mathrm{CvO}_{2}\right)(19) \\
& \text { Oxygen extraction }(\%)=\left(\mathrm{CaO}_{2}-\mathrm{CvO}_{2}\right) \cdot \mathrm{CaO}_{2}^{-1} \cdot 100
\end{aligned}
$$

All data were analyzed using one-way blocked analysis of variance for repeated measures. If a significant difference was found, Dunnett's or Neuman-Keul's post hoc test was used to compare the experimental mean to the baseline value in each measurement phase (nonanemic or anemic) and to compare the nonanemic versus the anemic phase at each measurement point (baseline or cold stress) (20). A value of $p<0.05$ was considered significant. All data are displayed as the mean \pm SEM.

\section{RESULTS}

Measured and calculated experimental values appear in Tables 1,2 , and 3 , respectively. As shown, cardiac output did not change during cold stress in either study phase despite a significant increase in heartrate (Table 1). Mean arterial blood pressure did not change during environmental cold stress in either phase of study. The arterial and mixed venous oxygen contents decreased along with the reduction in hematocrit. The mixed venous oxygen content declined during cold stress in both phases of study.

$\mathrm{VO}_{2}$ increased significantly during environmental cold stress in the nonanemic phase (Table 2). However, in the anemic phase of the study, the increase in $\mathrm{VO}_{2}$ was limited during environmental cold stress and, despite increased oxygen extraction, was significantly lower than the $\mathrm{VO}_{2}$ observed during cold stress in the nonanemic phase of study.

While the $\mathrm{pH}$ did not change during cold stress in either study phase, the $\mathrm{pCO}_{2}$ declined significantly during cold stress with anemia (Table 3). The arterial $\mathrm{pO}_{2}$ did not change during cold stress in either study phase although the $\mathrm{pO}_{2}$ during cold stress with anemia was higher than seen in the nonanemic phase. Base excess decreased during cold stress in both study phases.

Environmental and deep rectal temperatures during both phases of the study are displayed in Figures 1 and 2, respectively. As shown, there were no differences in the magnitude or rate of decline in environmental temperature between the study phases (Fig. 1). While deep rectal temperature was significantly decreased after 30,45 , and 60 min of cold stress in both study phases, the decline in temperature with anemia was significantly greater after $60 \mathrm{~min}$ of cold stress (Fig. 2). Figure 3 depicts the rate of change in deep rectal temperatures for each phase by plotting the difference $\left(T_{0}-T_{x}\right)$ between $T_{0}$ and $T_{x}$ versus time. 
Table 1. Measured experimental values (mean $\pm S E M, n=8$ )

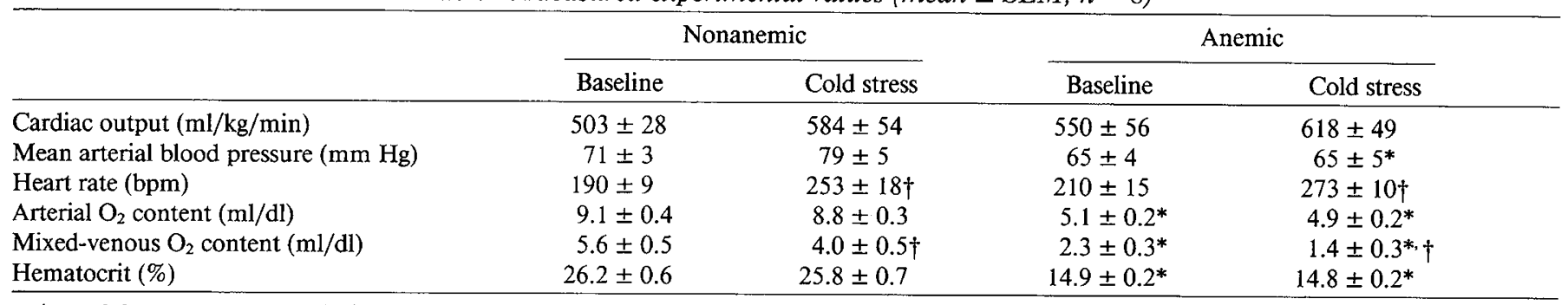

${ }^{*} p<0.05$ versus nonanemic for same environmental temperature.

$\dagger p<0.05$ versus baseline for same study phase.

Table 2. Calculated experimental values (mean $\pm S E M, n=8$ )

\begin{tabular}{cccccc}
\hline & \multicolumn{2}{c}{ Nonanemic } & \multicolumn{2}{c}{ Anemic } \\
\cline { 2 - 5 } & Baseline & Cold stress & Baseline & Cold stress \\
\hline$\dot{\mathrm{VO}}_{2}(\mathrm{ml} / \mathrm{kg} / \mathrm{min})$ & $17.6 \pm 1.8$ & $28.8 \pm 1.3^{*}$ & & $16.7 \pm 2.1$ & $21.1 \pm 1.7 \dagger$ \\
$\mathrm{O}_{2}$ extraction $(\%)$ & $39.5 \pm 4.7$ & $56.1 \pm 3.0$ & $56.2 \pm 4.2 \dagger$ & $70.3 \pm 4.2^{*,} \dagger$ \\
\hline
\end{tabular}

$* p<0.05$ versus baseline for same study phase.

$\dagger p<0.05$ versus nonanemic for same environmental temperature.

Table 3. Arterial blood gases (mean $\pm S E M, n=8$ )

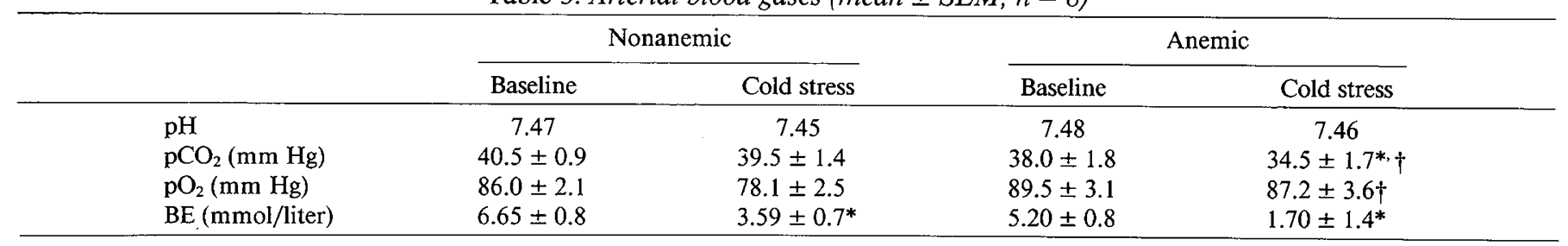

${ }^{*} p<0.05$ versus baseline for same study phase.

$\dagger p<0.05$ versus nonanemic for same environmental temperature.

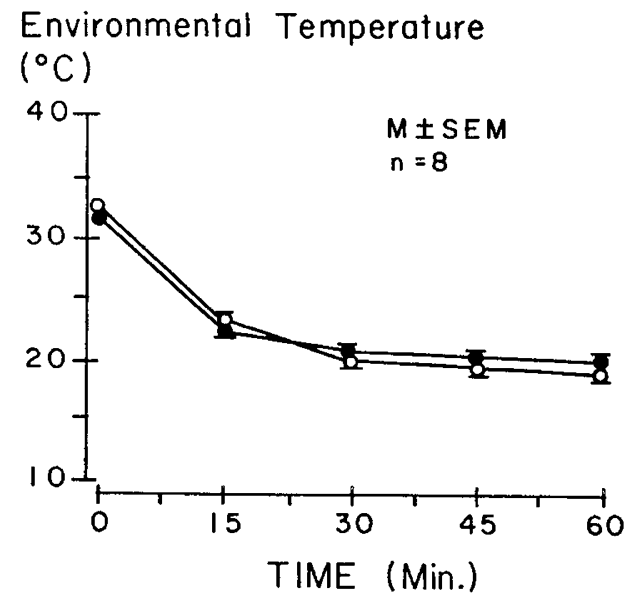

Fig. 1. Environmental temperatures during the nonanemic $(\bullet)$ and anemic $(O)$ study phases.

As shown, the rate of decline in deep rectal temperature with anemia was continuous and differed significantly from the nonanemic study phase at both points beyond 30 min of environmental cold stress.

\section{DISCUSSION}

We chose the newborn piglet as an animal model because of its thermoinsulative similarities to the human infant. These

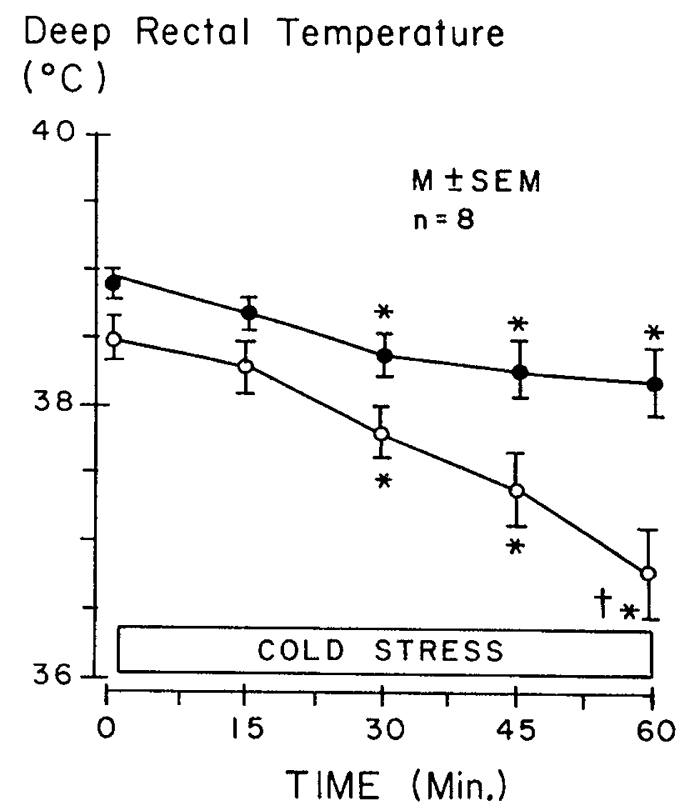

Fig. 2. Deep rectal temperatures during the nonanemic $(\bullet)$ and anemic $(O)$ study phases. Time zero measurements were obtained while in a warm environment. Measurements at 15, 30, 45 and 60 min were obtained while in a cold environment. ${ }^{*} \mathrm{p}<0.05$ versus time zero (warm environment) for same study phase. $\dagger p<0.05$ versus nonanemic for same measurement time. 
Change in Deep Rectal Temperature $T_{0}-T_{x}\left({ }^{\circ} \mathrm{C}\right)$

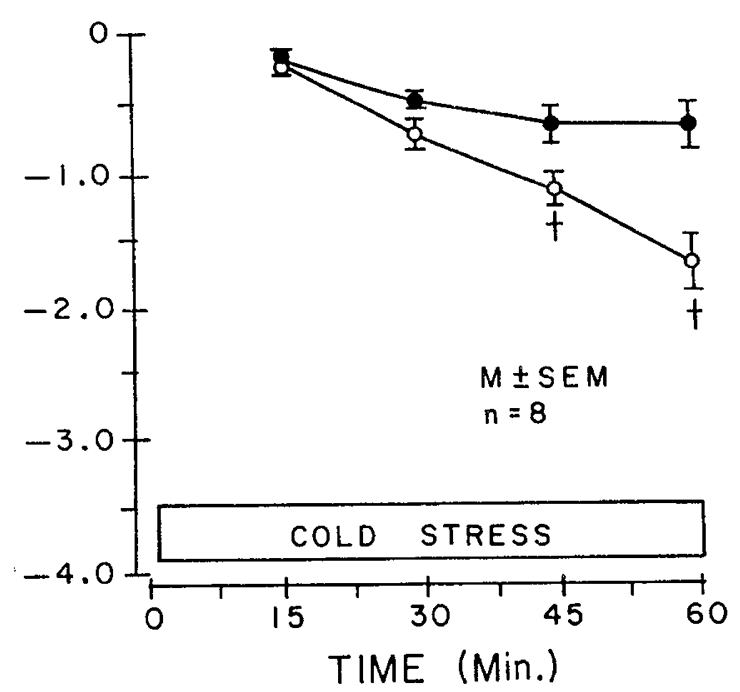

Fig. 3. Rate of change in deep rectal temperature during the nonanemic $(\bullet)$ and anemic $(O)$ study phases, plotted as the difference $\left(\mathrm{T}_{0}-\right.$ $\left.T_{x}\right)$ between time zero $\left(T_{0}\right)$ and cold stressed $\left(T_{x}\right)$ deep rectal temperatures versus time. $\dagger p<0.05$ versus nonanemic for same measurement time.

similarities include the lack of a thick hair coat, a large surface area to mass ratio, low body fat, and the ability to increase tissue insulation with peripheral vasoconstriction $(21,22)$. These characteristics result in a range of thermoneutral air temperatures which is slightly lower than the human, preterm infant $(23,24)$. Thermal differences with the human infant relate primarily to the nature and magnitude of heat production. Piglets have a basal oxygen consumption of $15-20$ versus $5-8 \mathrm{ml} / \mathrm{kg} / \mathrm{min}$ in newborn infants $(23,25)$. Moreover, piglets lack brown adipose tissue, relying on shivering thermogenesis when in a cold environment $(3,26)$. The latter property might seem to preclude the use of the piglet as a model during thermal stress. However, the intent of our study was to provoke heat production with an attendant increase in oxygen demand in the thermogenic tissue of the piglet. The site of heat production, therefore, became less important than its magnitude of change.

The mean thermoneutral air temperature in both study phases for our piglets was lower than the expected critical air temperature for newborn piglets $\left(31.6-32.8^{\circ} \mathrm{C}\right.$ versus $\left.34^{\circ} \mathrm{C}\right)$. However, the difference might be explained by our use of a plexiglass study chamber which would have the effect of a radiant heat shield. A radiant heat shield does not reduce total heat loss when in a thermoneutral environment; rather it reduces radiant heat loss, necessitating a decrease in air temperature in order to increase convective heat loss and avoid increasing body temperature (27). Thus, the air temperature necessary to maintain a thermoneutral mean operative temperature is reduced with a radiant heat shield.

We noted a significant decrease in deep rectal temperature during cold stress in the nonanemic phase of the study (Fig. 2). However, the mean deep rectal temperature remained within normal limits for piglets of this age $(1,11,12)$. Moreover, deep rectal temperature had plateaued by 30 min after the onset of cold stress (the nadir of the air temperature) and did not further change during the remainder of the nonanemic study phase. Conversely, deep rectal temperature declined continuously during cold stress in the anemic study phase with true body core hypothermia $\left(<38^{\circ} \mathrm{C}\right)$ observed at all measurement points beyond $15 \mathrm{~min}$ of cold stress (Fig. 2).

The magnitude of cold stress imposed in our study was expected to increase oxygen consumption to $40-70 \%$ of the summit metabolic response in newborn piglets (1). Thus, under typical circumstances for piglets of this postnatal age and weight, heat production should have been adequate to maintain body core temperature during an environmental cold stress of $18-22^{\circ} \mathrm{C}$ (1). Indeed, environmental temperatures as low as $5^{\circ} \mathrm{C}$ have been tolerated without hypothermia for up to $8 \mathrm{~h}$ in newborn piglets (1). The latter results were obtained under conditions where oxygen-carrying capacity was not limited. While limitation of resting $\mathrm{VO}_{2}$ with anemia has been previously demonstrated in newborn lambs (5), the decrease in red cell mass was less marked in our experiments, and a normal heart rate, mean arterial blood pressure, and $\dot{\mathrm{VO}}_{2}$ were observed with anemia while in a thermoneutral environment. During cold stress, we observed thermogenic failure with anemia; the expected $64 \%$ increase in $\mathrm{VO}_{2}$ and heat production was limited to a $21 \%$ increase (Table 2). Thus, reduction of oxygen-carrying capacity was not compensated by proportionate increases in cardiac output or oxygen extraction. The decrease in the oxygen availability-to-demand ratio resulted in limited $\dot{\mathrm{V}} \mathrm{O}_{2}$ and heat production with a resultant fall in deep rectal temperature to hypothermic levels. This suggests that total specific insulation in the piglet is at or near maximum at an environmental temperature $14-18^{\circ} \mathrm{C}$ above the lower limit of tolerance without hypothermia. Thus, one might speculate that heat production is the more critical factor in the maintenance of thermoregulatory stability when environmental temperatures are well below the thermoneutral zone. While this is not a novel concept, recognition is particularly important in light of a recent study which suggests that the thermogenic response of low birth weight infants is impaired during early postnatal life (28). The latter study suggests to us that low birth weight infants in the first weeks of life may be quasi-poikilothermic, depending heavily on total specific insulation and the temperature of the thermal environment for maintenance of a normal, core body temperature. This, in turn, emphasizes the importance of carefully controlling environmental temperatures during early postnatal life in this vulnerable cohort of patients.

Evidence exists to suggest that low birth weight infants who are chronically exposed to low grade environmental cold stress have increased subcutaneous fat accumulation (29) and may have increased thermogenic potential (30). Moreover, advancing neuromuscular maturity with increasing postnatal age improves the ability of these infants to assume postures of increasing flexion, reducing the skin surface area available for heat exchange with the environment. Thus, the 6-wk-old, low birth weight infant is an adequate thermoregulator under the circumstance of normal oxygen-carrying capacity. However, the thermal environment, which is well controlled in the first days of postnatal life, may be less rigorously attended to during the convalescent phase of illness, particularly if air temperature servocontrol is used (25). Moreover, there is a natural, postnatal decline in red cell mass which reached a nadir at 6-8 wk, depending on gestational age as well as other clinical correlates such as the occurrence of hemorrhagic events, amount of phlebotomy, number of transfusions, etc. (31). As low birth weight infants approach the nadir in red cell mass, the major criterion for transfusion therapy has generally been the emergence of symptoms such as apnea, tachycardia, or a heart murmur (32). Thus, it is not uncommon to allow the hematocrit to drift downward, as low or lower than $25 \%$, a $40 \%$ reduction from a "normal" hematocrit of $40 \%$. In our study, a $40 \%$ reduction in the hematocrit from baseline levels in newborn piglets resulted in a limitation of heat production during cold stress. While the duration of cold stress in our study was probably longer than would be seen in a clinical setting with human infants ( $30 \mathrm{~min}$ at the nadir of cold stress), the magnitude of cold stress was comparable to exposing a human infant to typical nursery room air temperature (33). Thus, anemic, low birth weight infants could potentially be exposed to a thermal environment within which they cannot mount a successful thermogenic response. This remains speculative and must be viewed 
in terms of our experimental model. We produced an acute, isovolemic decline in red cell mass which differs from the insidious development of anemia seen in newborn infants at $6-8 \mathrm{wk}$ of age. Compensatory mechanisms in the latter case (increased plasma volume, changes in P50) may differ from acute anemia. Any clinical correlation to the human infant is, thus, limited by the nature of our experimental model. Nonetheless, further study should be made of the convalescing, anemic, low birth weight infant to determine if a significant risk of hypothermia exists under typical nursery conditions. Moreover, further consideration should be given to the effects of reduced iron stores on energy expenditure. Studies of iron-deficient, nonanemic animals have suggested that oxidative phosphorylation is impaired in both skeletal muscle (34) and brown adipose tissue (35). The effect of iron deficiency on the human thermogenic response is unknown.

Acknowledgments. The authors thank Donna Piva for excellent technical assistance.

Presented in part at the annual meeting of the Society for Pediatric Research, May 1985 (Pediatr Res 19:353A, 1985).

\section{REFERENCES}

1. Mount LE 1963 Responses to thermal environment in newborn pigs. Fed Proc 22:818-823.

2. Alexander G, Bell AW, Hales JRS 1973 Effects of cold exposure on tissue blood flow in the new-born lamb. J Physiol (Lond) 234:65-77

3. Alexander G 1975 Body temperature control in mammalian young. Br Med Bull 31:62-68

4. Shepherd AP, Granger HJ, Smith EE, Guyton AC 1973 Local control of tissue oxygen delivery and its contribution to the regulation of cardiac output. Am J Physiol 225:747-755

5. Van Amerigen MR, Fouron JC, Bard H, Le Guennec JC, Prosmanne J 1981 Oxygenation in anemic newborn lambs with high or low oxygen affinity red cells. Pediatr Res 15:1500-1503

6. Cain SM 1977 Oxygen delivery and uptake in dogs during anemia and hypoxic hypoxia. J Appl Physiol 42:228-234

7. Cain SM, Chapler CK $1978 \mathrm{O}_{2}$ extraction by hind limb versus whole dog during anemic hypoxia. J Appl Physiol 45:966-970

8. Schwartz W, Frantz RA, Shoemaker WC 1981 Sequential hemodynamic and oxygen transport responses in hypovolemia, anemia, and hypoxia. Am $\mathbf{J}$ Physiol 241:H864-H871

9. Scopes JW, Ahmed I 1966 Indirect assessment of oxygen requirements in newborn babies by monitoring deep body temperature. Arch Dis Child 41:25-33

10. Laptook AR, Stonestreet BS, Oh W 1983 The effect of carotid artery ligation on brain blood flow in newborn piglets. Brain Res 276:51-54

11. Mount LE, Rowell JG 1960 Body size, body temperature, and age in relation to the metabolic rate of the pig in the first five weeks after birth. J Physiol (Lond) 154:408-416

12. Mount LE 1969 The respiratory quotient in the newborn pig. Br J Nutr 23:407-413

13. Guyton AC, Jones CE, Coleman TG 1973 Measurement of cardiac output by the direct Fick method. In: Circulatory Physiology: Cardiac Output and Its Regulation. WB Saunders, Philadelphia, pp 21-39

14. Cournand A, Riley RL, Breed ES, Baldwin ED, Richards Jr DW 1945 Measurement of cardiac output in man using the technique of catheterization of the right auricle or ventricle. J Clin Invest 24:106-116

15. Lister G, Walter TK, Versmold HT, Dallman PR, Rudolph AM 1979 Oxygen delivery in lambs: cardiovascular and hematologic development. Am J Physiol 237:H668-H675

16. Delivoria-Papadopoulos M, Martens RJ, Forster RE II, Oski FA 1974 Postnatal changes in oxygen-hemoglobin affinity and erythrocyte 2, 3-diphosphoglycerate in piglets. Pediatr Res 8:62-66

17. Hoffbrand BI, Forsyth RP 1969 Validity studies of the radioactive microsphere method for the study of the distribution of cardiac output, organ blood flow, and resistance in the conscious rhesus monkey. Cardiovasc Res 3:426-432

18. Heymann MA, Payne BD, Hoffman JIE, Rudolph Am 1977 Blood flow measurements with radionuclide-labeled particles. Prog Cardiovasc Dis 20:55-79

19. Kuipers JRG, Sidi D, Heymann MA, Rudolph AM 1982 Comparison of methods of measuring cardiac output in newborn lambs. Pediatr Res 16:594598

20. Winer BJ 1971 Single factor experiments having repeated measures on the same elements. In: Garmez YN, Solomon RL, Jones LV, Stevenson HW (eds) Statistical Principles in Experimental Designs. McGraw Hill, New York, pp 261-305

21. Mount LE Ingram DL 1971 Postnatal development, In: The Pig as an Animal Model. Academic Press, Inc, New York, p 111

22. Stombaugh DP, Roller WL, Adams T, Teague HS 1973 Temperature regulation in neonatal piglets during mild cold and severe heat stress. Am J Physiol 225:1192-1198

23. Mount LE 1959 The metabolic rate of the newborn pig in relation to environmental temperature and age. J Physiol (Lond) 147:333-345

24. Hey EN, Katz G 1970 The optimum thermal environment for naked babies. Arch Dis Child 45:328-334

25. Bell EF, Rios GR 1983 Air versus skin temperature servocontrol of infant incubators. J Pediatr 103:954-959

26. Mount LE 1968 Newborn pig. In: Climatic Physiology of the Pig. Edward Arnold Ltd, London, pp 60-96

27. Bell EF, Rios GR 1983 A double-walled incubator alters the partition of body heat loss of premature infants. Pediatr Res 17:135-140

28. Bell EF, Rios GR 1985 Maturation of body temperature control of prematurely born infants. Pediatr Res 19Part 2:334A(abstr)

29. Heimler R, Sumners JE, Grausz JP, Kien CL, Glaspey JC 1981 Thermal environment change in growing premature infants: effect on general somatic growth and subcutaneous fat accumulation. Pediatrics $68: 82-86$

30. Glass L, Silverman WA, Sinclair JC 1968 Effect of the thermal environment on cold resistance and growth of small infants after the first week of life. Pediatrics 41:1033-1046

31. Oski FA, Naiman JL, Stockman JA III, Pearson HA 1982 Anemia in the neonatal period. In: Hematologic Problems in the Newborn. WB Saunders Co, Philadelphia, pp 75-77

32. Usher RH 1981 The special problems of the premature infant. In: Avery GB (ed) Neonatology. JB Lippincott Co, Philadelphia, pp 230-261

33. Mayfield SR, Bhatia J, Nakamura KT, Rios GR, Bell EF 1984 Temperature measurement in term and preterm neonates. J Pediatr 104:271-275

34. Mackler B, Finch CA 1981 Studies of muscle dysfunction in iron deficiency in the rat. In: Oski FA, Pearson HA (eds) Iron Nutrition Revisited - Infancy, Childhood, Adolescence. Report of the Eighty-Second Ross Conference on Pediatric Research. Ross Laboratories, Columbus, OH, pp 82-88

35. Mackler B, Person R, Grace R 1985 Iron deficiency in the rat: effects on energy metabolism in brown adipose tissue. Pediatr Res 19:989-991 